\title{
Decrease in Skin Collagen Glycation with Improved Glycemic Control in Patients with Insulin-dependent Diabetes Mellitus
}

\author{
Timothy J. Lyons, ${ }^{\star *}$ Karen E. Bailie, ${ }^{\star}$ Daniel G. Dyer," John A. Dunn, and John W. Baynes" \\ *Department of Medicine, Altnagelvin Hospital, Londonderry, Northern Ireland, United Kingdom; ${ }^{\ddagger}$ Sir George E. Clark Metabolic Unit, \\ Royal Victoria Hospital, Belfast, Northern Ireland, United Kingdom; and $\$$ Department of Chemistry, and \\ "School of Medicine, University of South Carolina, Columbia, South Carolina 29208
}

\begin{abstract}
Glycation, oxidation, and nonenzymatic browning of protein have all been implicated in the development of diabetic complications. The initial product of glycation of protein, fructoselysine (FL), undergoes further reactions, yielding a complex mixture of browning products, including the fluorescent lysine-arginine cross-link, pentosidine. Alternatively, FL may be cleaved oxidatively to form $N^{t}$-(carboxymethyl)lysine (CML), while glycated hydroxylysine, an amino-acid unique to collagen, may yield $N^{\epsilon}$-(carboxymethyl)hydroxylysine (CMhL). We have measured FL, pentosidine, fluorescence (excitation $=328$ $\mathrm{nm}$, emission $=378 \mathrm{~nm}$ ), CML, and CMhL in insoluble skin collagen from 14 insulin-dependent diabetic patients before and after a 4-mo period of intensive therapy to improve glycemic control. Mean home blood glucose fell from 8.7 \pm 2.5 (mean \pm 1 SD) to $6.8 \pm 1.4 \mathrm{mM}(P<0.005)$, and mean glycated hemoglobin $\left(\mathrm{HbA}_{1}\right)$ from $11.6 \pm 2.3 \%$ to $8.3 \pm 1.1 \%(P<0.001)$. These changes were accompanied by a significant decrease in glycation of skin collagen, from $13.2 \pm 4.3$ to $10.6 \pm 2.3 \mathrm{mmol} \mathrm{FL} / \mathrm{mol}$ lysine $(P<0.002)$. However, levels of browning and oxidation products (pentosidine, CML, and CMhL) and fluorescence were unchanged. These results show that the glycation of longlived proteins can be decreased by improved glycemic control, but suggest that once cumulative damage to collagen by browning and oxidation reactions has occurred, it may not be readily reversed. Thus, in diabetic patients, institution and maintenance of good glycemic control at any time could potentially limit the extent of subsequent long-term damage to proteins by glycation and oxidation reactions. (J. Clin. Invest. 1991. 87:1910-1915.) Key words: glycation • nonenzymatic browning - Maillard reaction • diabetes • oxidation
\end{abstract}

\section{Introduction}

The mechanisms underlying the development of the complications of diabetes are not fully understood. Even the relationship between glycemic control and the risk of developing complications remains unclear, although there is now a consensus that hyperglycemia does, in itself, play an important role in the

Address reprint requests to Dr. Timothy J. Lyons, Division of Endocrinology, Metabolism, and Nutrition, Medical University of South Carolina, 171 Ashley Avenue, Charleston, SC 29425, which is Dr. Lyons's current address.

Received for publication 30 October 1990 and in revised form 29 January 1991.

\footnotetext{
J. Clin. Invest.

(c) The American Society for Clinical Investigation, Inc. $0021-9738 / 91 / 06 / 1910 / 06 \$ 2.00$

Volume 87, June 1991, 1910-1915
}

development of retinopathy, nephropathy, and neuropathy (1). The processes of glycation and nonenzymatic browning of proteins provide an attractive hypothesis to link hyperglycemia with the development of complications (2-4). The first step in this reaction pathway, glycation, involves the nonenzymatic condensation of glucose with free amino groups in the protein, primarily the $\epsilon$-amino groups of lysine residues, forming the Amadori adduct, fructoselysine (FL) ${ }^{1}$ (Fig. 1). FL may react further to initiate a complex series of reactions, which lead to the accumulation of covalently attached brown and fluorescent products, cross-links, and other chemical modifications in proteins. These reactions are known collectively as Maillard or nonenzymatic browning reactions $(5,6)$. This reaction is readily illustrated by the browning and cross-linking of proteins on incubation with glucose in physiological buffers in vitro.

A number of chemical and physical changes occur in human skin collagen with age. Fluorescence, cross-linking, and resistance to enzymatic degradation increase with age, while solubility and elasticity decrease (reviewed in 7). In diabetes, in concert with increased glycation (8-10) and nonenzymatic browning (11-13) of collagen, these age-related changes in the physical and chemical properties of collagen appear to be accelerated (11-15). This suggests a role for glucose and nonenzymatic browning reactions in the development of age-like chemical and functional alterations of collagen in diabetes. Although the extent of glycation of skin collagen does not appear to correlate directly with the presence of complications in diabetes $(9$, 10), the long-term effect of increased glycation, i.e., the browning reaction, may be more relevant. Thus, in groups of insulindependent diabetic patients, matched for age and duration of diabetes, there is a significant correlation between skin collagen fluorescence and the severity of retinopathy, nephropathy, arterial stiffness, and joint stiffness (16). Increased free-radical-mediated oxidative damage to biomolecules, including both lipids and proteins, has also been proposed as a mechanism contributing to the development of diabetic complications (reviewed in $17,18)$. Indeed, free radical reactions may in themselves generate fluorescent products and cross-links in proteins (19), and thus the changes in collagen with age and in diabetes may be the combined result of increases in glycation, browning, and oxidation reactions.

Several distinct chemical products of glycation and browning reactions of protein have now been measured in human proteins. These compounds (Fig. 1) include the Amadori adduct, FL, and three products of later stages of the Maillard

1. Abbreviations used in this paper: $\mathrm{CMhL}, N^{-}$-(carboxymethyl)hydroxylysine; CML, $N^{*}$-(carboxymethyl)lysine; FL, $N^{*}$-(1-deoxy-fructose-1-yl)L-lysine; $\mathrm{HbA}_{1}$, hemoglobin $\mathrm{A}_{1}$; MHBG, mean home blood glucose. 


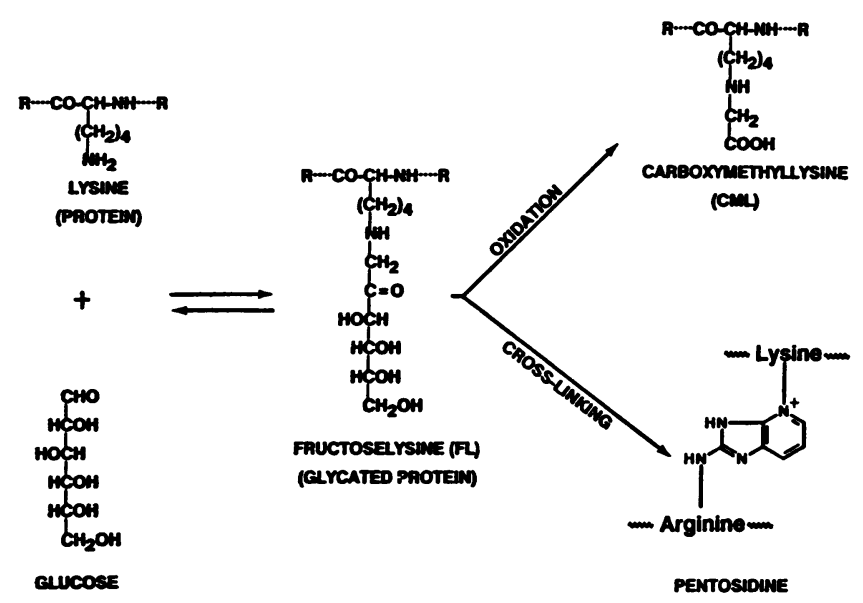

Figure 1. Maillard reaction pathways for formation of fructoselysine, pentosidine, and $N^{t}$-(carboxymethyl)lysine. FL is the Amadori compound, the first stable intermediate in the Maillard reaction. CML and the analogous compound $\mathrm{CMhL}$ (not shown), are formed by oxidative cleavage of Amadori adducts to lysine and hydroxylysine, respectively. The mechanism of formation of the fluorescent crosslink, pentosidine, is unknown.

reaction: pentosidine ${ }^{2} \quad(20-23), \quad N^{\epsilon}$-(carboxymethyl)lysine (CML) (24-27), and $N^{\epsilon}$-(carboxymethyl)hydroxylysine (CMhL) (27). The concentration of the initial product, FL, in long-lived proteins, such as lens proteins $(26,28)$ and skin collagen (27), increases in response to hyperglycemia in diabetes. Among the later products of the Maillard reaction, pentosidine is a fluorescent cross-link formed between lysine and arginine residues during the browning process (20-23), while CML and $\mathrm{CMhL}$, which are colorless, are formed by oxidative cleavage of carbohydrate adducts to lysine and hydroxylysine residues in protein, respectively (24-27). All three of these late-stage products of the Maillard reaction require oxygen for their formation $(20,24,25)$, i.e., they are either direct products of oxygen radical reactions or are formed by further reaction of oxidation products. In addition, they all accumulate gradually with age in skin collagen (27), and at an accelerated rate in diabetes $(21,23)$.

In this study, we have measured FL, pentosidine, CML, and $\mathrm{CMhL}$ and Maillard-type fluorescence (excitation (Ex) $=328 \mathrm{~nm}$, emission $(\mathrm{Em})=378 \mathrm{~nm})$ in insoluble skin collagen from patients with insulin-dependent diabetes, both before and after a period of improved glycemic control. Our aim was to discover if improvements in control would lead to a decrease in the level of any of these Maillard reaction products in diabetic skin collagen, and thus, perhaps, to a reversal of the potentially damaging effects of glycation, browning, and oxidation to longlived proteins in diabetes.

2. The compound Maillard Fluorescent Product \#1 (MFP-1) described in references 22 and 23 was originally identified as a fluorescent crosslink formed during browning and cross-linking of proteins by glucose. MFP-1 was isolated and characterized recently in our laboratory and shown by nuclear magnetic resonance spectroscopy and mass spectrometry to be identical to the compound, pentosidine, previously characterized by Sell and Monnier $(20,21)$. There is some uncertainty about whether pentosidine is formed in vivo from ribose $(20,21)$, glucose $(22$, $23)$, or other sugars (23a).

\section{Methods}

Patient selection. Patients (eight male, six female) with insulin-dependent diabetes mellitus, who were in relatively poor glycemic control, but motivated to improve, were recruited from the diabetes clinics of Altnagelvin Hospital, Londonderry, and the Royal Victoria Hospital, Belfast, Northern Ireland. Their mean age was 31.9 $\pm 10.5(19-51)$ yr (mean \pm SD, range), and mean duration of diabetes $12.5 \pm 10.6(0-38)$ yr. Three patients had newly diagnosed diabetes. Of the remainder, 10 were receiving twice daily injections of regular and NPH (Isophane) insulin, and one a single daily injection. Mean daily insulin dose was $74 \pm 11(52-88)$ U. The study was approved by the Ethical and Human Subjects Committees of the participating institutions, and informed consent was obtained from all volunteers.

Study design. After an initial assessment, each patient was taught to perform home blood glucose monitoring using a Memory Glucometer (Ames Div., Miles Laboratories Inc., Elkhart, IN) and was given a Memory Glucometer on loan for the duration of the study. Patients performed blood glucose measurements four times daily (before meals and at bedtime) throughout the study. For a 2-wk "run-in" period before the first skin biopsy, no effort was made to alter glycemic control. During this period, home blood glucose monitoring results were recorded, and hemoglobin $\mathrm{A}_{1}\left(\mathrm{HbA}_{1}\right)$ was measured on two occasions.

At the end of the run-in period, a full-thickness, elliptical $(1.0 \times 0.5$ $\mathrm{cm}$ ) skin biopsy was obtained, under local anesthesia, from the upper inner aspect of the buttock. The biopsy samples were washed in saline and stored at $-70^{\circ} \mathrm{C}$. Patients then entered a program of intensive management to improve glycemic control, and were seen on an individual basis by one of us ( $T$. Lyons or K. Bailie) at least once every two weeks. At each visit, the patients received appropriate individual education, including advice on the adjustment of insulin dosage. Between visits, one of us was available at all times to give advice by telephone. Each patient was also assessed initially, and subsequently reviewed, as necessary, by a dietitian. Throughout the study, $\mathrm{HbA}_{1}$ measurements were performed every two weeks. The results of home blood glucose monitoring were analyzed using the Ames "Glucofacts" program, and were expressed as "mean home blood glucose" (MHBG) on a weekly basis. At the conclusion of the study, a second skin biopsy was obtained from the corresponding site on the opposite buttock. The mean interval between first and second skin biopsies was $120 \pm 19$ (92-157) d.

Analytical procedures. $\mathrm{HbA}_{1}$ was measured by agar gel electrophoresis (29); the normal range in our laboratory is 3.6-7.2\%. Insoluble collagen was isolated from skin biopsy samples by mechanical scraping and solvent extraction as previously described (9). The preparation of $N^{\alpha}$ formyl- $N^{*}$-fructoselysine (the standard for the measurement of FL), $\mathrm{CML}$, and $\mathrm{CMhL}$ have been described previously $(24,25,27)$. A radioactive pentosidine standard was prepared from glucose, $N$-acetylarginine, and $N^{\alpha}$-acetyl-[4,5- $\left.{ }^{3} \mathrm{H}\right]$ lysine of known specific radioactivity, and purified by reversed phase HPLC (23a). Levels of FL, CML, CMhL, and lysine in insoluble collagen were measured by gas chromatography/mass spectroscopy with selected ion monitoring (SIM-GC/MS), as previously described in detail $(26,27)$. Briefly, for measurement of FL, collagen samples were hydrolyzed in $7.8 \mathrm{~N} \mathrm{HCl}\left(24 \mathrm{~h}, 110^{\circ} \mathrm{C}\right.$, under $\mathrm{N}_{2}$ ), yielding $40 \%$ conversion of FL to the analyte, furosine $(26,27,30)$. Because of partial conversion of FL to CML during the hydrolysis reaction (and possible conversion of glycated hydroxylysine to $\mathrm{CMhL}$ ), $\mathrm{CML}$ and $\mathrm{CMhL}$ were measured separately in $\mathrm{NaBH}_{4}$-reduced samples (27). Furosine (formed during acid hydrolysis of FL), CML, and CMhL were measured as their $N$,o-trifluoroacetyl methyl ester derivatives by SIM-GC/MS. The assays were standardized using standard curves prepared by standard addition, and the concentrations were normalized to the lysine (for FL and CML) or hydroxylysine (for CMhL) content of the collagen. The pentosidine content of skin collagen was measured, following $\mathrm{NaBH}_{4}$-reduction and hydrolysis in $6 \mathrm{~N} \mathrm{HCl}\left(24 \mathrm{~h}\right.$ at $\left.110^{\circ} \mathrm{C}\right)$, by reversed phase HPLC using fluorometric detection $(E x=328 \mathrm{~nm}$, $\mathrm{Em}=378 \mathrm{~nm})(22,23 \mathrm{a})$. Quantitation was based on fluorescence area units, using a standard curve prepared with known amounts of authentic pentosidine, and normalized to the lysine content of the protein. For 
measurement of fluorescence $(\mathrm{Ex}=328 \mathrm{~nm}, \mathrm{Em}=378 \mathrm{~nm})$, collagen was digested with pepsin $(5 \%, \mathrm{wt} / \mathrm{wt})$ in $0.5 \mathrm{M}$ acetic acid (adjusted to pH 2 with $6 \mathrm{M} \mathrm{HCl}$ ), for $24 \mathrm{~h}$ at $37^{\circ} \mathrm{C}$. The samples were clarified by centrifugation for measurement of fluorescence. More than $98 \%$ of the hydroxyproline content of the skin sample, determined as previously described (9), was solubilized by this method. The fluorescence readings were normalized to the hydroxyproline content of the solution. For each analysis all samples were analyzed together in a single batch to avoid interassay variations. All laboratory work on the samples was also done "blind", i.e., with no knowledge of sample identity.

Statistics. Results are expressed throughout as mean \pm 1 SD. Differences between groups before and after improved glycemic control were compared using a paired $t$ test.

\section{Results}

Measurements of both MHBG and $\mathrm{HbA}_{1}$ (Fig. 2) show that there were significant improvements in glycemic control in the patient group during the course of this study. The overall differences and statistical analyses for these and other measurements discussed below are summarized in Table I. Fig. 3 shows the results of all the analyses for individual patients. It is apparent that, in addition to MHBG (Figs. $2 A$ and $3 A$ ) and $\mathrm{HbA}_{1}$ (Figs. $2 B$ and $3 B$ ), the extent of glycation of skin collagen also decreased significantly between the beginning and end of the study (Fig. $3 C$ and Table I). Glycation of collagen correlated significantly with MHBG $(r=0.65, P<0.02)$ and $\mathrm{HbA}_{1}(r$ $=0.89, P<0.0001)$ at the beginning, but not at the end, of the study. Similarly, MHBG during the 2-wk run-in period correlated significantly with initial $\mathrm{HbA}_{1}(r=0.56, P<0.05)$, but, as might be expected, this correlation was lost with improved glycemic control. Over the course of the study, the relative decrease in individual patient $\mathrm{HbA}_{1}$ ([initial-final]/initial) corre-

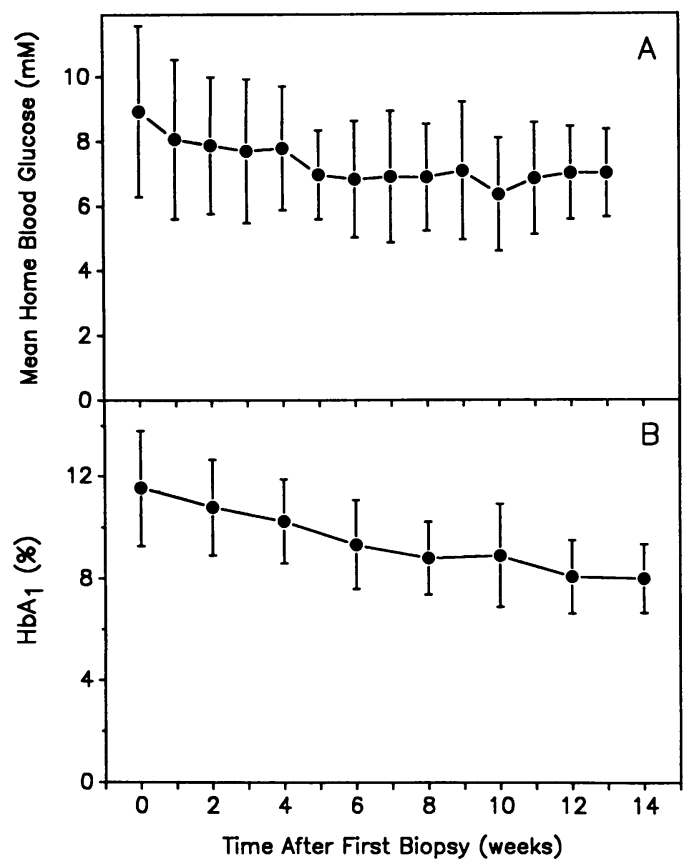

Figure 2. Sequential mean home blood glucose $(A)$ and $\mathrm{HbA}_{1}(B)$ results (mean $\pm 1 \mathrm{SD}$ ) for all 14 patients during the course of the study. The first skin biopsies were performed at time 0 .
Table I. Glycation and Oxidation Products in Insoluble Skin Collagen before and after Improved Glycemic Control

\begin{tabular}{lccc}
\hline \multicolumn{1}{c}{ Measurement } & Before & After & $P^{\ddagger}$ \\
\hline MHBG $(m M)$ & $8.7 \pm 2.5$ & $6.8 \pm 1.4$ & $<0.005$ \\
& $(4.0-12.8)$ & $(4.0-9.2)$ & \\
$\mathrm{HbA}_{1}(\%)$ & $11.6 \pm 2.3$ & $8.3 \pm 1.1$ & $<0.001$ \\
& $(76-16.6)$ & $(6.8-10.2)$ & \\
mmol FL/mol Lys & $13.2 \pm 4.3$ & $10.6 \pm 2.3$ & $<0.002$ \\
& $(7.2-22.7)$ & $(7.1-15.2)$ & \\
mmol CML/mol Lys & $0.78 \pm 0.46$ & $0.78 \pm 0.45$ & $\mathrm{NS}$ \\
& $(0.20-1.81)$ & $(0.14-1.86)$ & \\
mmol CMhL/mol Hyl & $2.18 \pm 1.06$ & $2.19 \pm 1.11$ & $\mathrm{NS}$ \\
& $(0.73-4.40)$ & $(0.49-4.48)$ & \\
$\mu$ mol pentosidine/mol Lys & $9.6 \pm 6.6$ & $9.7 \pm 6.4$ & $\mathrm{NS}$ \\
& $(1.5-22.5)$ & $(1.0-23.7)$ & \\
fluorescence U/ $\mu \mathrm{g}$ Hyp & $1.25 \pm 0.62$ & $1.22 \pm 0.51$ & $\mathrm{NS}$ \\
& $(0.34-2.55)$ & $(0.40-2.33)$ &
\end{tabular}

* Mean $\pm \mathrm{SD}$; ranges shown in parentheses.

${ }^{\ddagger}$ Significance estimated by paired $t$ test; NS, $P>0.1$.

lated significantly with the relative decreases in MHBG ( $r$ $=0.68, P<0.01)$ and FL in collagen $(r=0.72, P<0.005)$. Thus, changes in mean blood glucose concentration were mirrored by changes in glycation of both hemoglobin and collagen. This is apparent in Fig. 3, $A-C$, which shows visually that the greatest reductions in collagen FL occurred in those patients with highest initial FL values and who achieved the greatest decreases in MHBG and $\mathrm{HbA}_{1}$.

As shown in Fig. 3, $D-G$ and summarized in Table I, levels of CML, CMhL, pentosidine, and total fluorescence were unaffected by the 4-mo period of improved glycemic control. All of these parameters showed wide variations among individuals, reflecting differences in age (Fig. 3), as well as duration and severity of diabetes. There were no significant correlations of MHBG, $\mathrm{HbA}_{1}$, or collagen FL with CML, CMhL, pentosidine, or total fluorescence.

One other important observation made in this study is summarized in Fig. 4 and its legend. In diabetic patients, either at the beginning or end of the study, there was a strong correlation between any two of the measures of long-term chemical modification of collagen, i.e., nonenzymatic browning products (pentosidine), oxidation products (CML and CMhL), and total fluorescence. Thus, the four parameters measured in this study provide a consistent assessment of the extent of Maillard reaction damage to collagen.

\section{Discussion}

Collagen, in its various forms, is a ubiquitous protein in the body. Collagen abnormalities may therefore have widespread consequences, such as interference with basement membrane function in small vessels and glomeruli, or with the processes of growth and remodelling of tissues. Such problems are well recognized features of long-term diabetes. Increased glycation and nonenzymatic browning of collagen and other structural proteins by glucose is thought to be one of perhaps several mechanisms contributing to pathophysiological changes characteris- 

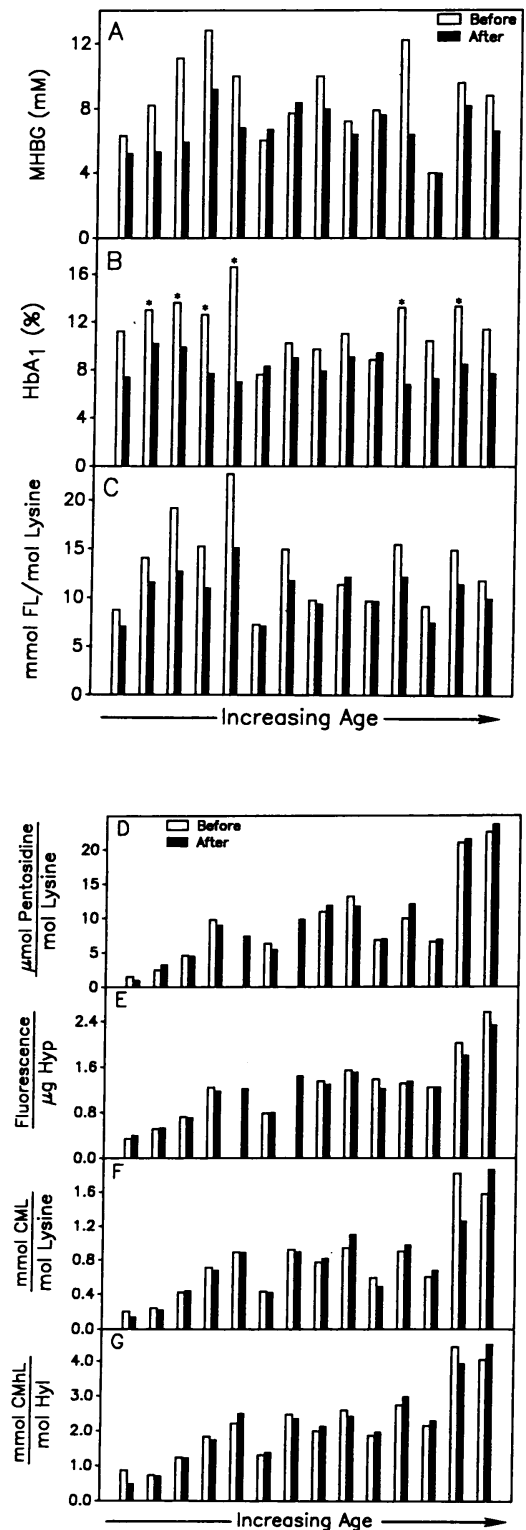

Figure 3. Individual changes in indices of glycemic control $(A, B)$, and glycation $(C)$, nonenzymatic browning $(D$ $E)$, and oxidation $(F$, $G)$ of collagen during the course of the study. Two data points are missing from the pentosidine $(D)$ and total fluorescence $(E)$ results, because of insufficient sample. Asterisks in B denote patients with initial $\mathrm{HbA}_{1}>12 \%$.

tic of aging (31) and the development of the complications of diabetes $(3,5,6,16)$. The extent of glycation of long-lived proteins is directly related to ambient glucose concentration (2628 ) and does not change significantly with age in the nondiabetic population $(26-28,32,33)$. While a number of earlier studies have shown that glycation of collagen is increased in response to hyperglycemia in diabetes $(8-10,15)$ and have found a strong correlation between glycation of hemoglobin and collagen $(9,10)$, our work demonstrates that glycation of human skin collagen may be significantly reduced within as short a time as a 4-mo period of improved glycemic control. To our knowledge only one other study (34) has addressed the question of reversibility of glycation of collagen. In that case the investigators found no decrease in glycation of tail tendon collagen in diabetic rats treated with insulin for an 8-wk period. The failure to detect differences in collagen glycation in these animal experiments may be explained by the shorter period studied.

Because of the impracticality of maintaining constant glycemia and obtaining multiple skin biopsies from patients, it is difficult to estimate an exact half-time for reversal of glycation of human skin collagen. However, the results of this study suggest that the half-time for response of collagen glycation to improvements in glycemic control may be as short as 4 mo. This conclusion is drawn from analysis of individual percent decreases in $\mathrm{HbA}_{1}$ and collagen FL, normalized to the percent decrease required to achieve the means of the nondiabetic population $\left(5.5 \% \mathrm{HbA}_{1}\right.$, and $4.6 \mathrm{mmol} \mathrm{FL} / \mathrm{mol} \mathrm{Lys} \mathrm{in} \mathrm{skin} \mathrm{colla-}$ gen) (27). For example, the response in collagen glycation was calculated as $\left.100 \times\left(F L_{\mathrm{i}}-F L_{\mathrm{f}}\right) / F L_{\mathrm{i}}-F L_{\mathrm{m}}\right)$, where $\mathrm{FL}_{\mathrm{i}}, \mathrm{FL}_{\mathrm{f}}$ refer to the initial and final measurements of $\mathrm{mmol} \mathrm{FL} / \mathrm{mol}$ Lys in collagen, and $\mathrm{FL}_{\mathrm{m}}=4.6 \mathrm{mmol} \mathrm{FL} / \mathrm{mol} \mathrm{Lys} \mathrm{in} \mathrm{collagen,}$ the mean value for the nondiabetic population (27). By this analysis there was an average $45 \%$ decrease in $\mathrm{HbA}_{1}$ and $25 \%$ decrease in glycation of collagen $(r=0.68, P<0.01)$ toward the nondiabetic means. The greater response in $\mathrm{HbA}_{1}$ is consistent with the increased rate of turnover of hemoglobin, compared to skin collagen. The $25 \%$ decrease in glycation of collagen within a 4-mo period indicates that the upper limit for the half-time for reversal of collagen glycation is $\sim 8 \mathrm{mo}$. The actual half-time is undoubtedly shorter since none of the patients achieved normoglycemia instantaneously or maintained normoglycemia throughout the course of the study. For the six patients in poorest control at the beginning of the study (initial $\mathrm{HbA}_{1}>12.0 \%$, marked by an asterisk in Fig. $3 \mathrm{~B}$ ), the average decreases toward the nondiabetic means during the course of the study were $66 \%$ for MHBG, $64 \%$ for $\mathrm{HbA}_{1}$, and $36 \%$ for glycation of collagen (see Fig. 3, $A-C$ ). These results suggest that if glycemia were completely and instantaneously normalized at the beginning of the study (i.e., $100 \%$ decrease to normal in MHBG), it should have been possible to achieve a $50 \%$ decrease towards normal in glycation of collagen within the 4-mo period of our study, suggesting an actual half-time closer to 4 mo for reversal of the excessive glycation of collagen. A more rigorous mathematical analysis cannot be justified because of the lack of information about the kinetics of collagen glycation and the mechanisms by which collagen FL content was decreased.

There are a number of possible explanations for the decrease in glycation of collagen during improved glycemic control. All assume a decrease in the rate of glycation in response to the fall in ambient glucose concentration, plus some reaction in which the existing glucose adducts are consumed. Assuming negligible turnover of insoluble skin collagen (35-38), one possible explanation for the decrease in glycation is that the reaction of glucose with lysine may be reversible, the hexose being released as glucose and mannose stereoisomers, regener-

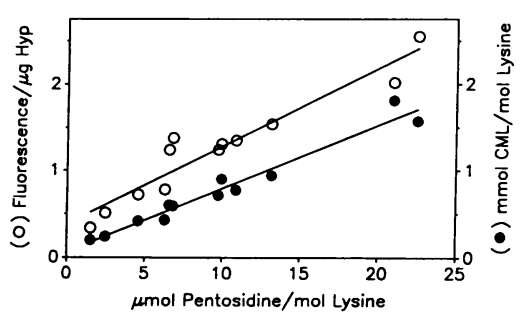

Figure 4. Correlations between pentosidine and total fluorescence or CML in skin collagen. These data are from analyses of the initial biopsy samples. All six of the possible paired correlations between pentosidine, fluorescence, $\mathrm{CML}$, and $\mathrm{CMhL}$ had $r \geq 0.9$ and $P \leq$ 0.001 in both initial and final collagen samples. 
ating the unmodified lysine residue. As reviewed in reference 39 , there is firm evidence for reversal of the Amadori rearrangement with model Amadori compounds (24), but little information on the rate or extent of reversal of glycation of proteins in vivo. It is also possible that the Amadori adduct is consumed in a forward reaction, resulting, for example, in the release of the carbohydrate in a modified form, such as 1- or 3-deoxyglucosone (40), again regenerating the unmodified lysine residue in collagen. The precision of our analyses do not permit us to determine whether the loss of FL in collagen is accompanied by an increase in the lysine content of the protein. Thus, it is also possible that the FL may be consumed in fragmentation and oxidation reactions, leading to formation of browning and oxidation products, including pentosidine, CML (CMhL), and other species. However, the further progress of these reactions should be limited by the decrease in the precursor, FL.

In contrast to $\mathrm{FL}$, levels of $\mathrm{CML}, \mathrm{CMhL}$, pentosidine, and total fluorescence in collagen did not respond to improved glycemic control within the period of this study. This is consistent with the fact that, to our knowledge, these compounds are stable and irreversible chemical modifications of protein; they are known to accumulate with age in long-lived proteins, such as lens crystallins (26) and the insoluble fraction of skin collagen $(21,27)$. Their constant concentration in collagen during the limited course of this study is also consistent with the metabolic inertness of insoluble human skin collagen (35-38), while the strong correlations between the concentrations of these compounds in collagen (Fig. 4) emphasize that they are all sensing the same chemical environment and stresses. While our results show that glycation of collagen may be reduced by improved glycemic control, they also indicate that browning and oxidation products formed during advanced stages of the Maillard reaction result in relatively permanent, perhaps irreversible, modification of the protein. These considerations add further weight to the argument that the establishment and maintenance of good glycemic control may inhibit the development of diabetic complications.

\section{Acknowledgments}

The authors wish to thank Drs. F. A. O'Connor and W. E. Parkes (Altnagelvin Hospital), and Drs. D. R. Hadden, J. A. Weaver, L. Kennedy, and A. B. Atkinson (Royal Victoria Hospital) for permission to study patients under their care. Dietetic consultations were provided by Mrs. E. McColgan (Altnagelvin Hospital) and Mrs. J. Holmes (Royal Victoria Hospital). We are grateful for the assistance of Mrs. G. M. Fleming and Mr. T. R. McCormick of the Department of Biochemistry, Altnagelvin Hospital.

This work was supported in part by Research Grant DK-19971 from the National Institute of Diabetes and Digestive and Kidney Diseases. The Ames Division, Miles Laboratories, Inc., generously provided the memory glucometers (Glucometer M) and personal computer used in these studies.

\section{References}

1. West, K. M. 1982. Hyperglycaemia as a cause of longterm complications. In Complications of Diabetes, 2 nd ed. H. Keen and R. J. Jarrett, editors. Edward Arnold, London. 13-18.

2. Kennedy, L. and J. W. Baynes. 1984. Non-enzymatic glycosylation and the chronic complications of diabetes: an overview. Diabetologia. 26:93-98.

3. Brownlee, M., H. Vlassara, and A. Cerami. 1984. Non-enzymatic glycosylation and the pathogenesis of diabetic complications. Ann. Intern. Med. 101:527537.
4. Editorial. 1986. Browning and diabetic complications. Lancet. i:11921193.

5. Baynes, J. W., and V. M. Monnier, editors. 1989. The Maillard Reaction in Aging, Diabetes and Nutrition. Alan R. Liss, Inc., New York. 410 pp.

6. Finot, P. A., H. U. Aeschbacher, R. F. Hurrell, and R. Liardon, editors. 1990. The Maillard Reaction in Food Processing, Human Nutrition and Physiology. Birkhäuser Verlag, Basel. 516 pp.

7. Kohn, R. R. 1978. Principles of Mammalian Aging. Prentice-Hall Inc., Englewood Cliffs, NJ. pp. 37-44.

8. Schnider, S. L., and R. R. Kohn. 1981. Effects of age and diabetes mellitus on the solubility and nonenzymatic glucosylation of human skin collagen. J. Clin. Invest. 67:1630-1635.

9. Lyons, T. J., and L. Kennedy. 1985. Nonenzymatic glycosylation of skin collagen in patients with limited joint mobility. Diabetologia. 28:2-5.

10. Vishwanath, V., K. E. Frank, C. A. Elmets, P. J. Dauchot, and V. M. Monnier. 1986. Glycation of skin collagen in Type I diabetes mellitus: correlation with long-term complications. Diabetes. 35:916-921.

11. Monnier, V. M., R. R. Kohn, and A. Cerami. 1984. Accelerated age-related browning of human collagen in diabetes mellitus. Proc. Natl. Acad. Sci. USA. 81:583-587.

12. Monnier, V. M., D. R. Sell, F. W. Abdul-Karim, and S. N. Emancipator. 1988. Collagen browning and cross-linking are increased in chronic experimental hyperglycemia: relevance to diabetes and aging. Diabetes. 37:868-872.

13. Dominiczak, M. H., J. Bell, N. H. Cox, D. C. McCruden, S. K. Jones, A. Y. Finlay, I. W. Percy-Robb, and B. M. Frier. 1990. Increased collagen-linked fluorescence in skin of young patients with Type I diabetes mellitus. Diabetes Care. 13:468-472.

14. Hamlin, C. R., R. R. Kohn, and J. H. Luschin. 1975. Apparent accelerated aging of human collagen in diabetes mellitus. Diabetes. 24:902-904.

15. Yue, D. K., S. McLennan, L. Delbridge, D. J. Handelsman, T. Reeve, and J. R. Turtle. 1983. The thermal stability of collagen in diabetic rats: correlation with severity of diabetes and non-enzymatic glycosylation. Diabetologia. 24:282285.

16. Monnier, V. M., V. Vishwanath, K. E. Frank, C. A. Elmets, P. J. Dauchot, and R. R. Kohn. 1986. Relation between complications of Type I diabetes mellitus and collagen-linked fluorescence. $N$. Engl. J. Med. 314:403-408.

17. Wolf, S. P. 1987. The potential role of oxidative stress in diabetes and its complications: novel implications for theory and practice. In Diabetic Complications. M. J. C. Crabbe, editor. Churchill-Livingstone Inc., New York. 167-220.

18. Lyons, T. J., S. R. Thorpe, and J. W. Baynes. 1990. Glycation and oxidation of proteins in aging and diabetes. In Glucose Metabolism, Diabetes and the Vascular Wall. N. Ruderman, M. Brownlee, and J. R. Williamson, editors. Oxford University Press, New York. In press.

19. Jones, A. F., and J. Lunec. 1987. Protein fluorescence and its relationship to free radical activity. Br. J. Cancer. 55(Suppl. VIII):60-65.

20. Sell, D. R., and V. M. Monnier. 1989. Structure elucidation of a senescence cross-link from human extracellular matrix: implication of pentoses in the aging process. J. Biol. Chem. 264:21597-21602.

21. Sell, D. R., and V. M. Monnier. 1990. End-stage renal disease and diabetes catalyze the formation of a pentose-derived crosslink from aging human collagen. J. Clin. Invest. 85:380-384.

22. Baynes, J. W., J. A. Dunn, D. G. Dyer, K. J. Knecht, M. U. Ahmed, and S. R. Thorpe. 1990. Role of glycation in development of pathophysiology in diabetes and aging. In Glycated Proteins in Diabetes Mellitus. R. G. Ryall, editor. Adelaide University Press, Adelaide, Australia. 219-236.

23. Dunn, J. W., D. G. Dyer, K. J. Knecht, S. R. Thorpe, D. R. McCance, K. Bailie, G. Silvestri, T. J. Lyons, and J. W. Baynes. 1990. Accumulation of Maillard reaction products in tissue proteins. In The Maillard Reaction in Food Processing Human Nutrition and Physiology. P. A. Finot, H. U. Aeschbacher, R. F. Hurrell, and R. Liardon, editors. Birkhäuser Verlag, Basel. 425-430.

23a.Dyer, D. G., J. A. Blackledge, S. R. Thorpe, and J. W. Baynes. 1991. Formation of pentosidine during non-enzymatic browning of proteins by glucose: identification of glucose and other carbohydrates as possible precursors of pentosidine in vivo. J. Biol. Chem. In press.

24. Ahmed, M. U., S. R. Thorpe, and J. W. Baynes. 1986. Identification of $\mathrm{N}^{*}$-(carboxymethyl)lysine as a degradation product of fructoselysine in glycated protein. J. Biol. Chem. 261:4889-4894.

25. Ahmed, M. U., J. A. Dunn, M. D. Walla, S. R. Thorpe, and J. W. Baynes. 1988. Oxidative degradation of glucose adducts to protein: formation of 3-(N*lysino-lactic acid from model compounds and glycated proteins. J. Biol. Chem. 263:8816-8821.

26. Dunn, J. A., J. S. Patrick, S. R. Thorpe, and J. W. Baynes. 1989. Oxidation of glycated proteins: age-dependent accumulation of $\mathrm{N}^{\prime}$-(carboxymethyl)lysine in human lens proteins. Biochemistry. 28:9464-9468.

27. Dunn, J. A., D. R. McCance, S. R. Thorpe, T. J. Lyons, and J. W. Baynes. 1991. Age-dependent accumulation of $\mathrm{N}^{*}$-(carboxymethyl)lysine and $\mathrm{N}^{\epsilon}$-(carboxymethyl)hydroxylysine in human skin collagen. Biochemistry. 30:1205-1210.

28. Patrick, J. S., S. R. Thorpe, and J. W. Baynes. 1990. Non-enzymatic glycosylation of protein does not increase with age in normal human lenses. $J$. Gerontol., Biol. Sci. 45:B18-23. 
29. Menard, L., M. E. Dempsey, L. A. Blankstein, H. Aleyassine, M. Wacks, and J. S. Soeldner. 1980. Quantitative determination of glycosylated hemoglobin $A_{1}$ by agar gel electrophoresis. Clin. Chem. 26:1598-1602.

30. Erbersdobler, H. F. 1986. Twenty years of furosine: better knowledge about the biological significance of Maillard reaction products in food and nutrition. Dev. Food Sci. 13:481-491.

31. Monnier, V. M. 1990 . Nonenzymatic glycosylation, the Maillard reaction and the aging process. J. Gerontol., Biol. Sci. 45:B105-111.

32. Schleicher, E., and O. H. Wieland. 1986. Kinetic analysis of glycation as a tool for assessing the half-life of proteins. Biochim. Biophys. Acta. 884:199-205.

33. Garlick, R. L., H. F. Bunn, and R. G. Spiro. 1988. Nonenzymatic glycation of basement membranes from human glomeruli and bovine sources: effect of diabetes and age. Diabetes. 37:1144-1150.

34. McLennan, S., D. K. Yue, M. Marsh, B. Swanson, L. Delbridge, T. Reeve, and J. R. Turtle. 1986. The prevention and reversibility of tissue non-enzymatic glycosylation in diabetes. Diabetic Med. 3:141-146.

35. Thompson, R. C., and J. E. Ballou. 1956. Studies of metabolic turnover with tritium as a tracer. V. The predominantly non-dynamic state of body constituents in the rat. J. Biol. Chem. 223:795-809.

36. Prockop, D. J., and K. I. Kivirikko. 1968. Hydroxyproline and the metabolism of collagen. In Treatise on Collagen, Vol. 2, Biology of Collagen. B. S. Gould, editor. Academic Press Ltd., London. 215-246.

37. Molnar, J. A., N. Alpert, J. F. Burke, and V. R. Young. 1986. Synthesis and degradation rates of collagens in vivo in whole skin of rate, studied with ${ }^{18} \mathrm{O}_{2}$ labeling. Biochem. J. 240:431-435.

38. Molnar, J. A., N. M. Alpert, D. A. Wagner, S. Miyatani, J. F. Burke, and V.R. Young. 1988. Synthesis and degradation of collagens in skin of healthy and protein-malnourished rats in vivo, studied by ${ }^{18} \mathrm{O}_{2}$ labeling. Biochem. J. 250:7176.

39. Baynes, J. W., N. G. Watkins, C. I. Fisher, C. J. Hull, J. S. Patrick, M. U. Ahmed, J. A. Dunn, and S. R. Thorpe. 1989. The Amadori product on protein: structure and reactions. In The Maillard Reaction in Aging, Diabetes and Nutrition. J. W. Baynes and V. M. Monnier, editors. Alan R. Liss, Inc., New York. 43-67.

40. Ledl, F., and E. Schleicher. 1990. New aspects of the Maillard Reaction in foods and in the human body. Angew. Chem. Int. Ed. Engl. 29:565-594. 